\title{
Studies on an efficient method for determining ethyl carbamate in the workplace air
}

\author{
J. Kowalska ${ }^{1}$ - A. Jeżewska ${ }^{1}$
}

Received: 9 March 2016/Revised: 15 April 2016/Accepted: 18 May 2016/Published online: 2 June 2016

(C) The Author(s) 2016. This article is published with open access at Springerlink.com

\begin{abstract}
In relation to the proposal to introduce an occupational exposure limit value for ethyl carbamate (EC) in Poland, a need to develop a sensitive method for determination of this carcinogenic substance in the workplace air was emerged. In the presented paper, a new method for its determination by high-performance liquid chromatography (HPLC) with fluorescence detector (FLD) is proposed. The method is based on the adsorption of EC on the cellulose filter, its extraction with water, further reaction of EC with 9-xanthydrol in acidic solution. Determination of the obtained EC derivative ( $N$-xanthyl ethyl carbamate) was then conducted in a reverse-phase system with acetonitrile and water mobile phase at a flow rate of $1 \mathrm{~mL} / \mathrm{min}$ on an Ultra C18 column of $250 \mathrm{~mm}$ by HPLC-FLD. Measurement range of $0.1-2 \mu \mathrm{g} / \mathrm{m}^{3}$ for a $1440 \mathrm{~L}$ of air sample was appropriate to the established maximum admissible concentration value of $1 \mu \mathrm{g} / \mathrm{m}^{3}$. The limit of detection is $0.142 \mathrm{ng} / \mathrm{mL}$, and the limit of quantification is $0.426 \mathrm{ng} / \mathrm{mL}$, respectively. The developed quantitative method makes it possible to determine ethyl carbamate in workplace air, which in turn allows determining exposure indicators and facilitates occupational risk assessment for the employees.
\end{abstract}

J. Kowalska

jokow@ciop.pl

1 Department of Chemical, Aerosol and Biological Hazards, Central Institute for Labour Protection - National Research Institute, Czerniakowska 16, 00-701 Warsaw, Poland
Keywords Ethyl carbamate - Urethane · 9-Xanthydrol . Liquid chromatography · Analytical method · Workplace . Analysis of air

\section{Introduction}

Ethyl carbamate (EC, urethane) of CAS no 51-79-6 is an odourless, crystalline solid of white colour, stable under normal conditions. Ethyl carbamate forms naturally in fermentation of foods, such as alcoholic beverages, soy sauce, yoghurt and cheese (Kim et al. 2000; Hong et al. 2007; Barlow and Schlatter 2010), and is present in tobacco smoke (Starek and Podolak 2009). Intentionally, EC is used as a component of paint thinners and removers, additive for cosmetic and pharmaceutical products as well as in mixtures based on methyl methacrylate for dental applications (EFSA 2007; IARC 2010; NTP 2011).

EC occupational exposure can occur by inhalation or skin contact (Szymańska et al. 2015). It has been classified by the International Agency for Research on Cancer (IARC) as a factor probably carcinogenic for humans (IARC 2010). The European Union has classified the compound as $1 \mathrm{~B}$, i.e. substances that may cause cancer (Regulation EC No 1272/2008). It was also found that in laboratory animals EC can cause lymphomas, leukaemia and cancers of lungs, liver, blood vessels and skin.

So far, there are no established workplace air exposure limits for EC in the world. In Poland, in 2015, at the meeting of the Group of Experts on Chemical Agents of the Interdepartmental Commission for Maximum Admissible Concentrations and Intensities for Agents Harmful to Health in the Working Environment, it was proposed to set a maximum allowable concentration (MAC) for ethyl carbamate at $1 \mu \mathrm{g} / \mathrm{m}^{3}$ (Szymańska et al. 2015). This 
created the need for a substance determination method within the range from 0.1 to 2 of the maximum admissible concentration, i.e. from 0.1 to $2 \mu \mathrm{g} / \mathrm{m}^{3}$.

Various analytical techniques have been applied for EC determination in food products, such as gas chromatography coupled with mass spectrometer (GC-MS) (Kim et al. 2013; Shin and Yang 2012) and high-performance liquid chromatography (HPLC) with fluorescence detector (FLD) after derivatization of EC (Madrera and Valles 2009; Valente et al. 2014). Deak et al. (2010) and Alberts et al. (2011) applied also HPLC with mass spectrometer. However, there are no methods for ethyl carbamate determination in workplace air in the available literature. Therefore, aim of this study was to analyse EC in workplace air and to carry out its risk assessment.

The experimental part of the study involved developing an analytical procedure for determining ethyl carbamate in the air, which could be applied to assess workers' exposure to this substance. For this reason, the method of individual dosimetry was chosen, in which sampler is worn in the worker's breathing zone for a period of at least $75 \%$ of the duration of a working shift (i.e. at least $6 \mathrm{~h}$ for an 8 -h shift). Thus, conducted measurements could account for all types of actions performed by the worker. During the active sampling process, aspirators (battery-powered pumps) attached to a sampler force the flow of a known air volume through it. The quantitative method makes it possible to determine carcinogenic ethyl carbamate in workplace air, which in turn allows determining the exposure indicators and facilitates occupational risk assessment for the employees.

\section{Materials and methods}

\section{Material and reagents}

The following reagents were used in the experiment: ethyl carbamate, methyl carbamate, urea, 9-xanthydrol, $2 \mathrm{~mol} / \mathrm{L}$ hydrochloric acid $(\mathrm{HCl})$, acetonitrile and methanol (SigmaAldrich, Germany), sodium chloride (POCh, Poland) and high-purity water obtained from Milli-Q equipment (Millipore Corporation, USA). HPLC pure reagents were used for the experiment.
Whatman GF/A fibreglass filters of $37 \mathrm{~mm}$ diameter (Whatman, England), cellulose filters of $37 \mathrm{~mm}$ diameter (POCh, Poland) for air sampling and 113 nylon syringe filters of $25 \mathrm{~mm}$ diameter and pore size of $0.45 \mu \mathrm{m}$ (Alltech, USA) for filtering solution before HPLC analysis were used. Additional equipment, such as glassware, volumetric flasks, $25-\mathrm{mL}$ conical flasks with stoppers, test tubes, pipettes and syringes, was used.

\section{Apparatus}

An Agilent Technologies (Germany) liquid chromatograph, series 1200 , with an online coupled fluorescence detector (FLD) was used in the experiment. Samples were injected with an autosampler. Ultra C18 column of dimensions $(250 \times 4.6 \mathrm{~mm}$ and $5 \mu \mathrm{m}$ particle size $)$, with a precolumn of dimensions: $10 \times 4.0 \mathrm{~mm}$ (Restek, USA) was applied. Gilair 5 aspirator (Sensidyne, USA) was used for collecting air samples. Mechanical shaker WL-2000 (JWElectronic, Poland) was used for EC recovery from filter and Sartorius TE214S analytical balance (Sartorius Corporation, USA) to weigh standard substances. EKS series cabinet desiccator (WSL, Poland) was used to store filters.

\section{Chromatographic conditions}

Determination of EC was conducted with an Ultra $\mathrm{C}_{18}$ HPLC column $(250 \times 4.6 \mathrm{~mm}, 5 \mu \mathrm{m})$ with a precolumn. Column temperature was set to $40^{\circ} \mathrm{C}$. Mobile phase of acetonitrile/water $(75: 25, v / v)$ at a flow rate of $1 \mathrm{~mL} / \mathrm{min}$ was applied. Volume of the sample injected onto the column was $10 \mu \mathrm{L}$. Fluorescence detector (FLD) was used at the wavelengths $\left(\lambda_{\mathrm{ex}}=238 \mathrm{~nm} / \lambda_{\mathrm{em}}=300 \mathrm{~nm}\right)$.

\section{Results and discussion}

\section{Air sampling and sample preparation}

Ethyl carbamate is a solid under normal conditions; therefore, filters must be used to isolate it from the air. Subsequently, the substance retained and concentrated on the filters is washed out with the properly selected liquid. 
Table 1 Selected results of EC adsorption on cellulose filters and fibreglass filters

\begin{tabular}{llc}
\hline Filter type & $\begin{array}{l}\text { Approximate substance } \\
\text { concentration in the air }\left(\mu \mathrm{g} / \mathrm{m}^{3}\right)\end{array}$ & $\begin{array}{l}\text { EC derivative peak area } \\
\text { in solutions after recovery }\end{array}$ \\
\hline Fibreglass filter & 2 & 29.9 \\
& 2 & 58.5 \\
Cellulose filter & 2 & 69.0 \\
& 2 & 1293.0 \\
& 2 & 1475.9 \\
& 2 & 1476.8 \\
\hline
\end{tabular}

In order to verify the conditions of air sampling, $50 \mu \mathrm{L}$ of a $57.6 \mu \mathrm{g} / \mathrm{mL}$ EC solution in methanol was applied onto fibreglass and cellulose filters $37 \mathrm{~mm}$ in diameter. After drying, the filters were placed in a cassette, for sampling the inhalable fraction, and then connected to an aspirator. Air was passed through the filter with a flow rate recommended by the manufacturer of the holder for sampling the inhalable fraction-i.e. $4 \mathrm{~L} / \mathrm{min}$ for $6 \mathrm{~h}$, which corresponds to $1440 \mathrm{~L}$. Air flow rate was controlled.

The obtained results presented in Table 1 indicate that a fibreglass filter does not retain ethyl carbamate from the air. Satisfactory results were obtained for the same tests carried out with the cellulose filter, and therefore, this type of filter was chosen for further experiments.

\section{Derivatization of EC}

Complete extraction of an analyte from filters of $37 \mathrm{~mm}$ diameter is usually carried out with large amounts of the eluent $(2.5-10 \mathrm{~mL})$, which dilutes the analyte. The concentration of an analyte achieved in this manner may be insufficient for its determination at the assumed concentration level. Due to this, the analyte was enriched by converting EC to its derivative and further liquidliquid extraction with salting out, as it was verified previously by Valente et al. (2014) during analysis of alcohol products.

Possibility of applying 9-xanthydrol as a derivatization reagent which, according to the literature (Madrera and Valles 2009; Valente et al. 2014), reacts with carbamates and produces a derivative that increases sensitivity of HPLC-FLD determination was also examined. The chromatographic conditions of HPLC-FLD make it possible to determine the reaction products with 9-xanthydrol (Fig. 1).

Schematically, air sample preparation process for analysis of EC is presented in Fig. 2. Air samples containing EC (1440 L) were collected on the filter. EC was extracted from filter with water, followed by a reaction with

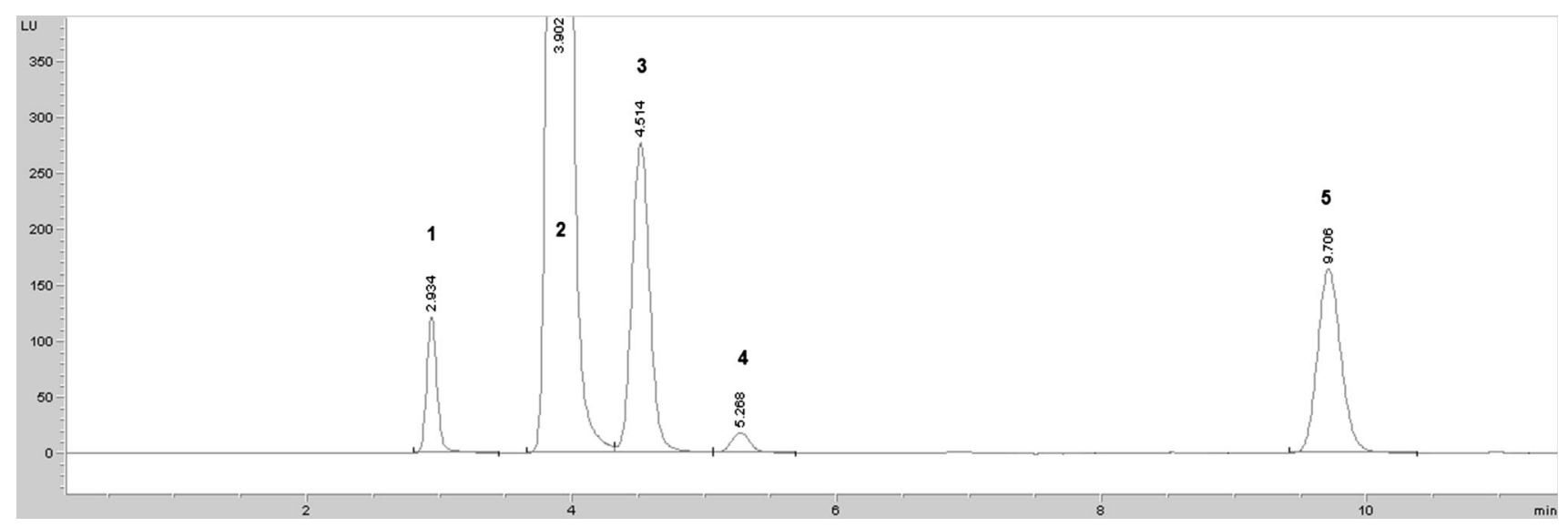

Fig. 1 Chromatogram of ethyl carbamate derivative in the presence of coexisting substances: 1 urea derivative, 2 9-xanthydrol, 3 methyl carbamate derivative, 4 ethyl carbamate derivative, 5 9-xanthydrol contamination. Determination conditions: HPLC-FLD $\left(\lambda_{\mathrm{ex}}=238 \mathrm{~nm} /\right.$ $\left.\lambda_{\mathrm{em}}=300 \mathrm{~nm}\right)$, Ultra $\mathrm{C} 18$ column $(250 \times 4.6 \mathrm{~mm}, 5 \mu \mathrm{m})$, column temp. $40{ }^{\circ} \mathrm{C}$; mobile phase $\mathrm{ACN}$ : $\mathrm{H}_{2} \mathrm{O}, 75: 25(\mathrm{v} / \mathrm{v})$; flow $1 \mathrm{~mL} / \mathrm{min}$ 


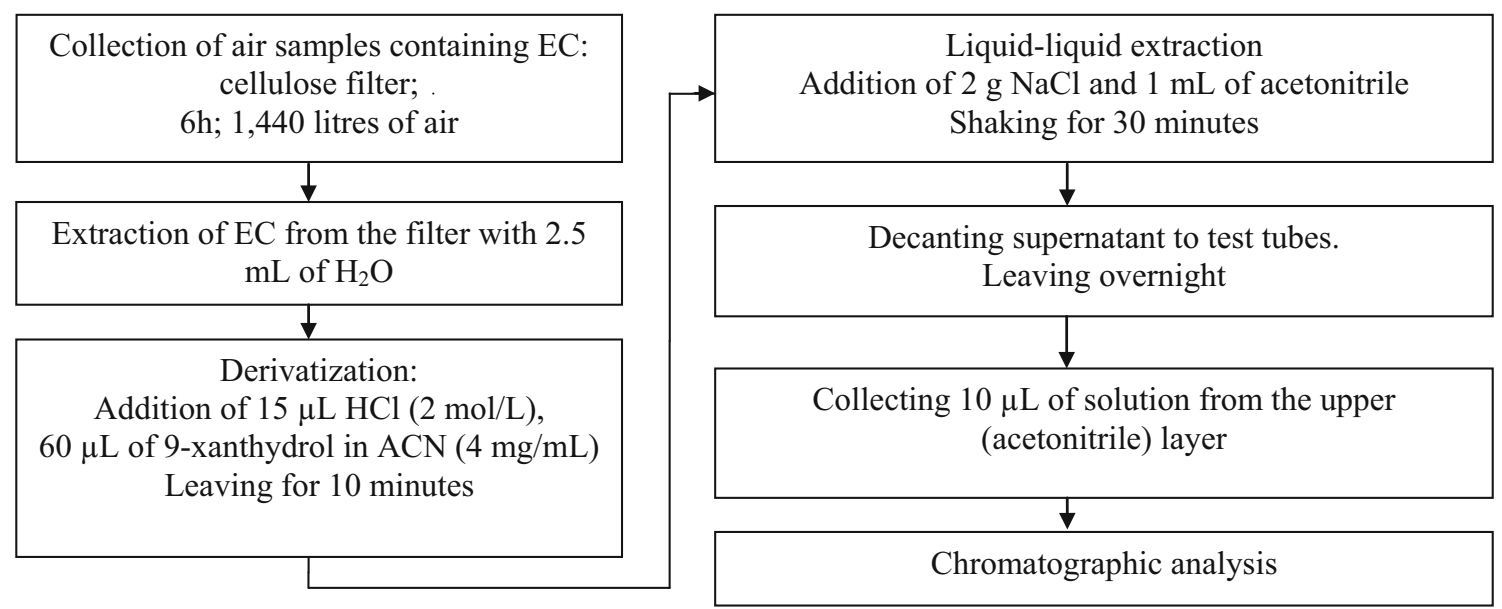

Fig. 2 Diagram of the sample preparation procedure for determining ethyl carbamate in air at workplaces

Table 2 Calibration parameters for three measurement series

\begin{tabular}{llll}
\hline Parameter & A series & B series & C series \\
\hline Calibration curve $y=b x+a$ & $y=508.47 x+30.65$ & $y=530.11 x+4.29$ & $y=510.14 x+15.30$ \\
Correlation coefficient & 0.9989 & 0.9999 & 0.9995 \\
Mean calibration coefficient & & 553.24 \\
Standard deviation for calibration coefficient & & 36.35 \\
Variability coefficient for calibration coefficient (\%) & & 6.57 \\
\hline
\end{tabular}

9-xanthydrol in acidic solution in order to obtain the required derivative ( $N$-xanthyl ethyl carbamate). Subsequently, both $\mathrm{NaCl}$ and $1 \mathrm{~mL}$ of acetonitrile were added in order to separate water layer from acetonitrile layer. Ethyl carbamate derivative in acetonitrile was determined chromatographically.

\section{Calibration and precision}

Due to the multi-step nature of the sample preparation process, the calibration curve was prepared by applying standard of EC solutions in methanol with increasing concentrations onto cellulose filters. In such case, there is no need to determine the recovery efficiency. Any potential loss of substance which results from consecutive steps of the sample preparation process will be identical during calibration and real sample analysis.
The calibration was carried out in the concentration range of $0.144-2.88 \mu \mathrm{g} / \mathrm{mL}$. The following concentrations of EC solution in methanol: $2.88 ; 4.32 ; 7.2 ; 14.4 ; 28.8$ and $57.6 \mu \mathrm{g} / \mathrm{mL}$ were prepared. Therefore, $50 \mu \mathrm{L}$ of each solution was separately applied onto filters. Three series of six filters in each were prepared. Working solutions in acetonitrile from each filter were obtained according to the diagram shown in Fig. 2. Table 2 shows the parameters which characterize the calibration curves described by the $y=b x+a$ equation. The calibration curves were linear for the studied concentration range.

In order to assess the precision of calibration, working standards were prepared in three series of eight working solutions in the following concentrations: 0.144, 1.44 and $2.88 \mu \mathrm{g} / \mathrm{mL}$ of $\mathrm{EC}$ in water. After derivatization and preparation for analysis as per Fig. 2, EC was determined by liquid chromatography. 
Table 3 Validation parameters of the method for the determination of ethyl carbamate

\begin{tabular}{ll}
\hline Parameter & Value \\
\hline Measurement range & $0.1 \div 2 \mu \mathrm{g} / \mathrm{m}^{3}$ \\
Sampled air volume & $1440 \mathrm{~L}$ \\
Range of calibration curve & $0.144 \div 2.88 \mu \mathrm{g} / \mathrm{mL}$ \\
Limit of detection (LOD) & $0.142 \mathrm{ng} / \mathrm{mL}$ \\
Limit of quantitation (LOQ) & $0.426 \mathrm{ng} / \mathrm{mL}$ \\
Total test precision & $5.94 \%$ \\
Total relative uncertainty & $12.88 \%$ \\
\hline
\end{tabular}

\section{Validation}

The described method for determination of EC in workplace air was validated according to PN-EN 482:2012 in terms of linearity, sensitivity, selectivity, precision and accuracy. The limit of detection (LOD) and the limit of quantitation (LOQ) were determined from the blank sample results. Validation data estimated for the developed method of ethyl carbamate's determination (for $1440 \mathrm{~L}$ of air sample within the measurement range of $0.1-2 \mu \mathrm{g} / \mathrm{m}^{3}$ ) are presented in Table 3 .

\section{Conclusion}

As a result of the conducted tests, an adequate cellulose filter was selected for adsorption of ethyl carbamate from the air. Before determination, it was subjected to derivatization with 9-xanthydrol. Derivation reagent was selected along with the conditions of its reaction with ethyl carbamate. Within the studied range $\left(0.1-2 \mu \mathrm{g} / \mathrm{m}^{3}\right)$, linear calibration curves were obtained. Preparation of the standard curve involving the step of sample preparation for analysis was proposed. Such an analysis method causes elimination of the recovery coefficient determination step and thus shortening the analysis time and reduction in reagent consumption. The developed quantitative method for the determination of concentrations of EC in workplace air can be used to estimate occupational exposure in reference to a maximum admissible concentration of $1 \mu \mathrm{g} / \mathrm{m}^{3}$ established in Poland.

Acknowledgments This paper is based on the results of a research task carried out within the scope of the third stage of the National Programme 'Improvement of safety and working conditions' partly supported in 2014-2016 - within the scope of research and development-by the Ministry of Science and Higher Education/National Centre for Research and Development. The Central Institute for Labour Protection-National Research Institute (CIOP-PIB), was the Programme's main coordinator.
Open Access This article is distributed under the terms of the Creative Commons Attribution 4.0 International License (http:// creativecommons.org/licenses/by/4.0/), which permits unrestricted use, distribution, and reproduction in any medium, provided you give appropriate credit to the original author(s) and the source, provide a link to the Creative Commons license, and indicate if changes were made.

\section{References}

Alberts P, Stander MA, De Villiers A (2011) Development of a novel solid-phase extraction, LC-MS/MS method for the analysis of ethyl carbamate in alcoholic beverages: application to South African wine and spirits. Food Addit Contam Part A Chem Anal Control Expo Risk Assess 28:826-839

Barlow S, Schlatter J (2010) Risk assessment of carcinogens in food. Toxicol Appl Pharm 243:180-190

Deak E, Gyepes A, Stefanovits-Banyai E, Dernovics M (2010) Determination of ethyl carbamate in palinka spirits by liquid chromatography electrospray tandem mass spectrometry after derivatization. Food Res Int 43:2452-2455

EFSA [European Food Safety Authority] (2007) Ethyl carbamate and hydrocyanic acid in food and beverages. EFSA J 551:1-44. http://www.efsa.europa.eu/sites/default/files/scientific_output/ files/main_documents/Contam_ej551_ethyl_carbamate_en_rev. 1,3.pdf. Accessed 14 July 2015

Hong KP, Kang YS, Jung DC, Park SR, Yoon JH, Lee SY, Ko YS, Kim SH, Ha SD, Park SK, Bae DH (2007) Exposure to ethyl carbamate by consumption of alcoholic beverages imported in Korea. Food Sci Biotechnol 16:975-998

IARC (2010) Alcohol consumption and ethyl carbamate. IARC monographs on the evaluation of carcinogenic risk of chemicals to humans, vol 96. World Health Organization International Agency for Research on Cancer, Lyon, pp 1281-1378

Kim YK, Koh E, Chung H, Kwon H (2000) Determination of ethyl carbamate in some fermented Korean foods and beverages. Food Addit Contam Part A Chem Anal Control Expo Risk Assess 17:469-475

Kim JH, Park J-M, Choi G-H, Kim Y-W (2013) Development of easy and efficient methods for quantitative analysis of ethyl carbamate using GC-MS in various fermented foods. Food Sci Biotechnol 22(3):599-603

Madrera RR, Valles BS (2009) Determination of ethyl carbamate in cider spirits by HPLC-FLD. Food Control 20:139-143

NTP [National Toxicology Program] (2011) Report on carcinogens, 12th edn. U.S. Department of Health and Human Services, Public Health Service, Research Triangle Park, pp 1-507 
Polish Standard PN-EN 482: Workplace exposure. General requirements for the performance of procedures for the measurement of chemical agents. Polish Committee for Standardization, 2012

Regulation (EC) No 1272/2008 of the European Parliament and of the Council of 16 December 2008 on classification, labelling and packaging of substances and mixtures, amending and repealing Directives 67/548/EEC and 1999/45/EC, and amending Regulation (EC) No 1907/2006. EU OJ L 353 of 31 December 2008

Shin H-S, Yang E-Y (2012) Simultaneous determination of methylcarbamate and ethylcarbamate in fermented foods and beverages by derivatization and GC-MS analysis. Chem Cent J 6:157
Starek A, Podolak I (2009) Carcinogenic effect of tabacco smoke. Rocz Panstw Zakl Hig-Annals of the National Institute of Hygiene 60(4):299-310

Szymańska J, Bruchajzer E, Frydrych B (2015) Ethyl carbamate. Documentation of proposed values of occupational exposure limits (OELs). PiMOŚP Princ Methods Assess Work Environ 3(85):67-106

Valente IM, Ramos RM, Gonçalves LM, Rodrigues JA (2014) Determination of ethyl carbamate in spirits using salting-out assisted liquid-liquid extraction and high performance liquid chromatography with fluorimetric detection. Anal Methods 6:9136-9141 